\title{
End Stage Renal Disease in a Child with Epidermolysis Bullosa
}

\author{
Felipe Cavagnaro ${ }^{1,2,3 *}$, María Joao Yubero ${ }^{2,3}$, Marcela Valenzuela4, Francis Palisson ${ }^{1,2,3}$ \\ ${ }^{1}$ Facultad de Medicina, Clínica Alemana-Universidad del Desarrollo, Santiago, Chile \\ ${ }^{2}$ Clínica Alemana de Santiago, Santiago, Chile \\ ${ }^{3}$ Fundación DEBRA-Chile, Santiago, Chile \\ ${ }^{4}$ Unidad de Nefrología Pediátrica, Hospital Guillermo Grant Benavente, Concepción, Chile \\ Email: "fcavagnaro@alemana.cl
}

Received 1 April 2016; accepted 2 July 2016; published 5 July 2016

Copyright (C) 2016 by authors and Scientific Research Publishing Inc.

This work is licensed under the Creative Commons Attribution International License (CC BY).

http://creativecommons.org/licenses/by/4.0/

(c) (i) 0pen Access

\begin{abstract}
Epidermolysis bullosa (EB) is an inherited connective tissue disease causing blisters in the skin and mucosal membranes. In severe cases, EB may be associated with renal damage through several mechanisms, mainly immunological ones. The present case described a young male with dystrophic recessive EB who developed an advanced chronic renal damage secondary to tubulointerstitial nephritis that was demonstrated by a renal biopsy. Unpublished previously, this complication should be considered among the possible causes of renal damage in EB. Also it is recommended a protocoled surveillance of renal and urinary tract complications in children with EB.
\end{abstract}

\section{Keywords}

Epidermolysis Bullosa, Tubulointerstitial Nephritis, Chronic Renal Failure, Dialysis

\section{Introduction}

Epidermolysis bullosa (EB) syndromes are a group of genetic mechanobullous skin disorders that share a common feature of blister formation occurring with little or minor trauma, and are classified nowadays under the group of genodermatoses. EB may be broadly differentiated into four main groups by the level at which the separation occurs: at the intraepidermal level (EB simplex), intra-lamina lucida (junctional EB), sub-basal lamina level (dystrophic EB) and Kindler syndrome. Further distinctions are made according to mode of inheritance, extent of disease (localized, generalized), associated features, and underlying genetic alterations [1]. New EB phenotypes, genotypes and modes of transmission have been identified recently, each of which has its own relative risk for the development of specific extracutaneous complications and/or premature death [2]. Among these,

"Corresponding author.

How to cite this paper: Cavagnaro, F., Yubero, M.J., Valenzuela, M. and Palisson, F. (2016) End Stage Renal Disease in a Child with Epidermolysis Bullosa. International Journal of Clinical Medicine, 7, 433-436.

http://dx.doi.org/10.4236/ijcm.2016.77045 
a small but important proportion may develop significant renal and urological complications which can have a major impact on their quality of life, morbidity and mortality [3]. The present article describes a child with dystrophic EB who developed end stage renal disease (ESRD) secondary to a chronic, although undetected, tubulointerstitial nephritis (TIN), an unreported renal complication of EB.

\section{Case Report}

A 13-year-old white male affected with severe generalized recessive dystrophic EB was evaluated in a regular health control by the medical team of DEBRA (Dystrophic Epidermolysis Bullosa Research Association)-Chile. He had a homozygous mutation (+/+) COL7A1: c.7708delG, exon 103 and clinically characterized by bilateral pseudo syndactyly, esophageal stricture, which required dilatation, recurrent corneal ulcers, chronic anemia and severe malnutrition. He was doing fine, asymptomatic, but with many skin lesions and blisters in his extremities. No laboratory test regarding renal function or abdominal ultrasound was done in the last 6 months. He had been receiving multivitamins, hydroxyzine, chlorpheniramine, zinc, famotidine and lactulose for the last 6 months, and occasionally non-steroidal anti-inflammatory drugs (NSAIDs) and systemic antibiotics for inter current infections. His urine output was normal, with no edema, blood pressure in normal range for age, sex and height. Among the lab test done, drew attention a serum creatinine of $2.4 \mathrm{mg} / \mathrm{dl}$ and BUN $48 \mathrm{mg} / \mathrm{dl}$. His phosphorus was $6 \mathrm{mg} / \mathrm{dl}$, calcium $8.2 \mathrm{mg} / \mathrm{dl}$, hematocrit 20.8\%, normal plasma electrolytes, venous blood $\mathrm{pH}$ of 7.28 and bicarbonate $16 \mathrm{mEq} / \mathrm{L}$. Urinalysis without hematuria, leucocyturia or casts, urine protein/creatinine ratio of 1.77. Renal ultrasound showed kidneys of normal size but with increased cortical echogenicity, the parenchymal blood flow was normal, with resistive index in normal range. Repeated serum creatinine one week later was 2.74 $\mathrm{mg} / \mathrm{dl}$. A renal biopsy was performed (Figure 1) showing multifocal tubular atrophy and interstitial fibrosis involving up to $50 \%$ of the examined tissue. Some of the atrophic tubules had prominently thickened and wrinkled basement membrane with a reduced diameter and a narrow lumen filled with eosinophilic homogeneous proteinaceous material. Non-atrophic tubules showed dilated and irregular lumen. Also a focally dense inflammatory cell infiltrate made up mainly of lymphocytes was seen. There was more than $50 \%$ of global glomerular sclerosis with thickening and delamination of Bowman's capsule of the remaining glomeruli and retraction of the glomerular tuft. By immunofluorescence, weak mesangial positivity for $\mathrm{C}_{3}$ and IgM was seen; there was no $\mathrm{C}_{3}$ or immunoglobulin deposition in tubulointerstitial compartment. On ultraestructural examination, the glomeruli showed slight wrinkling of the basement membrane, without irregular contours or dense deposits. The pathologist's findings were consistent with chronic tubulointerstitial nephritis. A tentative treatment with oral prednisone $2 \mathrm{mg} / \mathrm{kg} /$ day was initiated, with mild improvement of renal function (serum creatinine of $2.17 \mathrm{mg} / \mathrm{dl}$ ) for 3

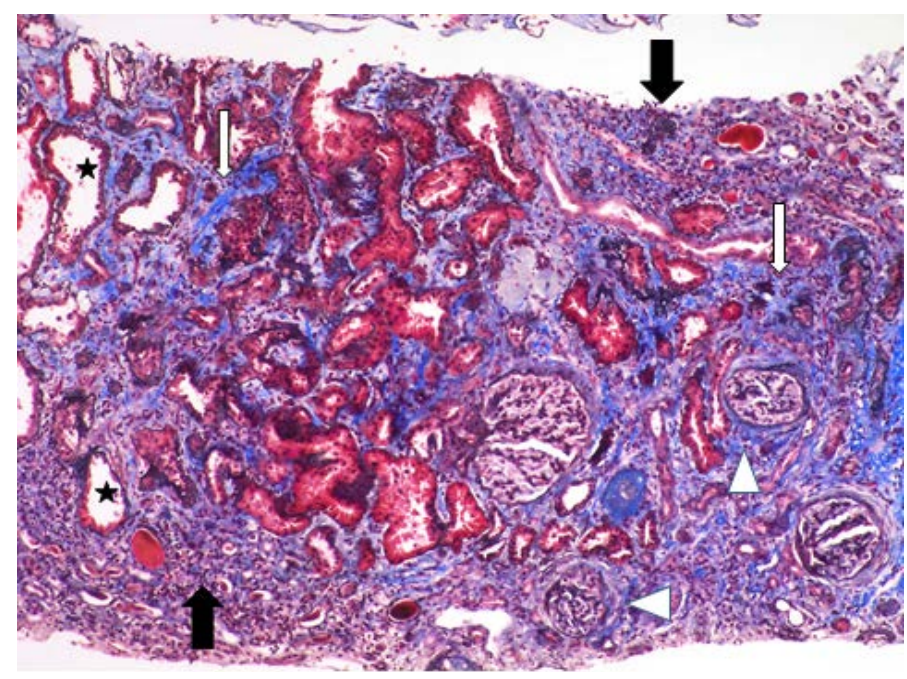

Figure 1. Renal histology stained with Masson's trichrome + Jones methenamine silver showing diffuse tubulointerstitial mononuclear infiltrate (black arrows), peri glomerular fibrosis (white arrow heads), interstitial fibrosis (white arrows) and tubular atrophy (asterics). ( $\times$ 200). 
months, but with further worsening of azotemia. Finally, the patient's renal function worsened progressively to the level of end stage renal disease, and was started on chronic peritoneal dialysis two years after the biopsy. Two more years later and due to a big communicating hydrocele, the patient was switched to chronic hemodialysis. Currently the patient is stable on dialysis but without perspective of kidney transplantation because of parents refusal.

\section{Discussion}

The genodermatoses are a large group of inherited single-gene disorders with skin manifestations. Many of these disorders are rare. However, the recognition of their skin findings is important not only for the initiation of appropriate dermatologic therapy, but also for the detection of other associated abnormalities in these frequently multisystem disorders, including malignancy [1]. Genitourinary involvement in EB has been widely reported [3] [4]. The renal parenchyma itself may be affected in patients with EB, particularly those with the more severe forms.

The pathogenesis of renal damage is complex and several factors are involved: a) frequent antibiotic therapies based on aminoglycosides, notoriously nephrotoxic, used to treat renal and skin infections; b) cytokine release, particular amyloid A protein, which, in EB patients, may lead to renal failure; c) immunocomplexes, deposited in glomerular capillary basement membranes, or in the mesangium, resulting in post-infectious glomerulonephritis, IgA glomerulonephritis, or mesangial proliferative glomerulonephritis [5], besides the renal damage secondary to urinary tract stenosis/obstruction and associated infections [3] [4]. All these conditions can lead to chronic renal failure, although it is a rare cause of death in pediatric population [6].

In our patient, the cause of severe renal dysfunction was identified histologically as a chronic TIN, an association not reported previously in children with EB. TIN is an immune-mediated cause of renal damage characterized by the presence of inflammatory cell infiltrate in the interstitium of the kidney. According to the etiology, TIN can be classified into two main types: non-infectious and infectious. Concerning the non-infectious causes, the use of certain drugs is either directly responsible for TIN or indirectly by creating a hypersensitivity reaction, mainly after the use of NSAIDs or $\beta$-lactam antibiotics [7]. The manifestation of the disease is either of sudden onset or, rarely, chronic with slow evolution leading to end-stage renal disease, as it occurred in our patient. We could not clarify the cause of this chronic TIN, being most probably related to the chronic (or acute) use of some drugs, as the way it happened with this child. Among the main possible culprit drugs we should include prescribed and unprescribed ones, as non-steroidal anti-inflammatory drugs and antibiotics frequently used in this disease. No evidence of characteristic infections associated with TIN [7] was detected previously. Besides that, chronic TIN might occur after a systemic disease that causes immunity disequilibrium such as sarcoidosis, lupus, Sjögren's syndrome, vasculitis and Crohn's disease [8]. EB may cause immunological alterations due to persistent inflammation and recurrent infections but its direct relationship with TIN has not been probed. With exception of EB acquisita, an autoimmune disease, the common EB is a genetic disorder without an autoimmune origin demonstrated so far [1].

Direct injury, high metabolic demands, or stimuli from various other forms of renal dysfunction activate tubular cells. These, in turn, interact with interstitial tissue elements and inflammatory cells, causing further pathologic changes in the renal parenchyma. The tissue response to these changes thus generates a feed-forward loop of kidney injury and progressive loss of function [9]. The treatment of TIN is very controversial, being the withdrawal of the offending agent the most important issue. The use of steroids in TIN has shown benefits in cases of drug-induced TIN within the first 2 weeks of diagnosis and before the progression of interstitial fibrosis [10]. In our case, the steroids were initiated too late and the renal failure continued progressing as expected, despite an initial improvement of the serum creatinine.

As mentioned before, the clinical presentation of chronic TIN uses to be slow and unrecognized. In our patient, without overt clinical symptoms/signs suggesting renal dysfunction, the diagnosis of this complication was greatly delayed, a situation that could be avoided if the patient had been in a tighter follow-up plan. It is recommended that a nephro-urological surveillance should be part of the routine evaluation from childhood EB [11]. In this sense, there are currently no published guidelines on how to monitor these patients. Almaani and Mellerio recommend a 6-monthly serum urea and electrolytes, blood pressure, and urinalysis be performed in all patients with recessive dystrophic EB and junctional EB. Annual ultrasound imaging in patients with junctional EB may also be warranted. If any abnormalities are detected, appropriate imaging or functional tests should be performed and specialist urological or renal opinions sought [12]. 


\section{Conclusion}

Nephro-urological complications are not uncommon in severe cases of EB. Renal damage from different mechanisms and pathogenesis may lead to advanced chronic renal failure. Our patient represents an unrecognized and unpublished cause of ESRD, diagnosed by a renal biopsy. Because patients with EB are frequently on many drugs, NSAIDs and antibiotics among them, TIN should be considered as a possible cause of kidney injury. This complication could have been recognized much earlier if it had followed a protocol tracking periodically nephrourological complications in these children. We strongly recommend a protocoled surveillance of renal and urinary tract complications in children with EB.

\section{Acknowledgements}

We want to thank Marcela Schultz M.D. for her invaluable help informing the renal histology of our cases with EB.

\section{Disclosure}

The authors of this manuscript declare to have no conflict of interest for its publication.

\section{References}

[1] Fine, J.D., Eady, R.A., Bauer, E.A., Bauer, J.W., Bruckner-Tuderman, L., Heagerty, A., Hintner, H., Hovnanian, A., Jonkman, M.F., Leigh, I., McGrath, J.A., Mellerio, J.E., Murrell, D.F., Shimizu, H., Uitto, J., Vahlquist, A., Woodley, D. and Zambruno, G. (2008) The Classification of Inherited Epidermolysis Bullosa (EB): Report of the Third International Consensus Meeting on Diagnosis and Classification of EB. Journal of the American Academy of Dermatology, 58, 931-950. http://dx.doi.org/10.1016/j.jaad.2008.02.004

[2] Fine, J.D. (2010) Inherited Epidermolysis Bullosa: Recent Basic and Clinical Advances. Current Opinion in Pediatrics, 22, 453-458. http://dx.doi.org/10.1097/MOP.0b013e32833bb74f

[3] Chan, S.M., Dillon, M.J., Duffy, P.G. and Atherton, D.J. (2007) Nephro-Urological Complications of Epidermolysis Bullosa in Paediatric Patients. British Journal of Dermatology, 156, 143-147. http://dx.doi.org/10.1111/j.1365-2133.2006.07516.x

[4] Fine, J.D., Johnson, L.B., Weiner, M., et al. (2004) Genitourinary Complications of Inherited Epidermolysis Bullosa (EB): Experience of the National EB Registry and Review of the Literature. The Journal of Urology, 172, 2040-2044. http://dx.doi.org/10.1097/01.ju.0000143200.86683.2c

[5] Tammaro, F., Calabrese, R., Aceto, G., Lospalluti, L., Garofalo, L., Bonifazi, E., Piccolo, T., Pannarale, G. and Penza, R. (2008) End-Stage Renal Disease Secondary to IgA Nephropathy in Recessive Dystrophic Epidermolysis Bullosa: A Case Report. Pediatric Nephrology, 23, 141-144. http://dx.doi.org/10.1007/s00467-007-0577-0

[6] Fine, J.D., Johnson, L.B., Weiner, M. and Suchindran, C. (2008) Cause-Specific Risks of Childhood Death in Inherited Epidermolysis Bullosa. The Journal of Pediatrics, 152, 276-280.

[7] Ulinski, T., Sellier-Leclerc, A.L., Tudorache, E., Bensman, A. and Aoun, B. (2012) Acute Tubulointerstitial Nephritis. Pediatric Nephrology, 27, 1051-1057. http://dx.doi.org/10.1007/s00467-011-1915-9

[8] Marcus, S.B., Brown, J.B., Melin-Aldana, H. and Strople, J.A. (2008) Tubulointerstitial Nephritis: An Extraintestinal Manifestation of Crohn's Disease in Children. Journal of Pediatric Gastroenterology \& Nutrition, 46, 338-341. http://dx.doi.org/10.1097/MPG.0b013e31806dc2c4

[9] Hodgkins, K. and Schnaper, W. (2012) Tubulointerstitial Injury and the Progression of Chronic Kidney Disease. Pediatric Nephrology, 27, 901-909. http://dx.doi.org/10.1007/s00467-011-1992-9

[10] González, E., Gutiérrez, E., Galeano, C., Chevia, C., de Sequera, P., Bernis, C., Parra, E.G., Delgado, R., Sanz, M., Ortiz, M., Goicoechea, M., Quereda, C., Olea, T., Bouarich, H., Hernández, Y., Segovia, B. and Praga, M., for Grupo Madrileño de Nefritis Intersticiales (2008) Early Steroid Treatment Improves the Recovery of Renal Function in Patients with Drug-Induced Acute Interstitial Nephritis. Kidney International, 73, 940-946. http://dx.doi.org/10.1038/sj.ki.5002776

[11] Fine, J.D., Johnson, L.B., Weiner, M., Stein, A., Cash, S., DeLeoz, J., Devries, D.T. and Suchindran, C., National Epidermolysis Bullosa (2004) Registry Inherited Epidermolysis Bullosa and the Risk of Death from Renal Disease: Experience of the National Epidermolysis Bullosa Registry. American Journal of Kidney Diseases, 44, 651-660. http://dx.doi.org/10.1016/S0272-6386(04)00935-7

[12] Almaani, N. and Mellerio, J. (2010) Genitourinary Tract Involvement in Epidermolysis Bullosa. Dermatologic Clinics, 28, 343-346. http://dx.doi.org/10.1016/j.det.2010.01.014 


\section{Submit or recommend next manuscript to SCIRP and we will provide best service for you:}

Accepting pre-submission inquiries through Email, Facebook, Linkedin, Twitter, etc A wide selection of journals (inclusive of 9 subjects, more than 200 journals)

Providing a 24-hour high-quality service

User-friendly online submission system

Fair and swift peer-review system

Efficient typesetting and proofreading procedure

Display of the result of downloads and visits, as well as the number of cited articles

Maximum dissemination of your research work

Submit your manuscript at: http://papersubmission.scirp.org/ 